\title{
Peer Review of Teaching: Sharing Best Practices
}

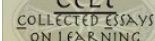

2015 CELT Vol. VIII celt.uwindsor.ca www.stlhe.ca

STLHE SAPES

\author{
Shaya Golparian, Judy Chan, Alice Cassidy \\ University of British Columbia
}

In this paper, we share examples of best peer review of teaching practices, drawing on our involvement in the design and implementation of the Peer Review of Teaching program at the Centre for Teaching, Learning and Technology. We review the history of the Peer Review of Teaching Initiative at the University of British Columbia and explain key aspects of the interactive peer review of teaching session we facilitated at STLHE 2014. We provide examples generated by participants of that session, as well as participants of Centre for Teaching, Learning and Technology workshops on peer review of teaching. We share future steps for the Peer Review of Teaching Program at $U B C$.

\section{Introduction}

工earning by conducting peer review of teaching? In what ways do you support colleagues who ask you to sit in on their classes and provide them with feedback?

Having been involved in different developmental stages of the Peer Review of Teaching (PRT) Program at the University of British Columbia (UBC), we led an interactive session on this topic at STLHE 2014, intended for people who have conducted peer reviews of teaching. Our goals were to have participants explore classroom peer reviews from a variety of perspectives and to leave the session being able to help colleagues at their institutions and contexts in new ways.

In this paper, we will provide an overview of our PRT Initiative at UBC, describe key elements of the conference session, and place peer review in the context of related work.

\section{What do we mean by Peer Review of Teaching?}

Chism (2007) defines peer review of teaching as a form of evaluation designed to provide feedback to instructors about their teaching in order to foster improvement or make personal and/or career decisions. Related terms are summarized by Cassidy and Lee (2011). Peer review of teaching occurs along a continuum from informal to formal. Informal peer review, usually conducted for developmental purposes, is often defined as formative peer review. Formal peer review, usually conducted for evaluation purposes, is defined as summative peer review. The terms formative and summative evaluation, first introduced by Scriven (1973) within the context of program evaluation, have now been widely adopted in the evaluation of teaching.

As noted in Cassidy and Lee (2011), The Center for Excellence in Learning and Teaching at Iowa State University conducted a literature review of peer evaluation of teaching, with links to best 
practices. Peer review has gained prominence internationally and for online teaching as well, such as through the Australian Learning and Teaching Council. While programs of peer review of teaching now take place at several institutions (for example: University of Waterloo, Kansas State University, University of Nebraska, etc.), it was less common when we started this process at UBC.

Classroom peer reviews can be a transformative process for both reviewee and reviewer as it provides an opportunity for the reviewee to have feedback on their teaching, and it exposes the reviewer to different styles and techniques of teaching. Cassidy and Johnson (2006) designed and first implemented a 4-hour workshop, Developing your skills as a Peer Reviewer: Introductory workshop. The model, a three-part process, involves a preobservation meeting, class observation, and a postobservation meeting. Notes taken at each of the three stages comprise a report that is provided to the reviewee. They may wish to include it in their teaching dossier or application for a job, promotion and/or tenure. Additional steps such as meeting with the students, and/or post-observation meeting reflection have been described elsewhere (Buskist, Ismail, \& Groccia, 2014; Hitchens, 2014).

Based on the Instructional Skills Workshop (ISW) model (http://iswnetwork.ca/about/iswprogram-in-detail/), the process is reviewee-focused and currently informs both formative and summative peer review of teaching processes. The model that Cassidy and Johnson (2006) developed and that Centre for Teaching, Learning and Technology (CTLT) continues to use fits the collaborative model described by Gosling (2014) where teaching is improved through constructive facilitated dialogue and self and mutual reflections. Reviewees may choose any aspect(s) of course design, teaching, student learning and/or assessment to be included during the review process.

\section{History of the Peer Review of Teaching Initiative at the University of British Columbia}

As will be explained below, the Formative PRT Program is one part of the broader Peer Review of Teaching Initiative at our institution. Peer Review began at UBC in 2006 as a request by one faculty member in Dentistry with one-year funding from the campus-wide Teaching and Learning Enhancement Fund. Cassidy and Johnson (2006), working at the Centre for Teaching and Academic Growth (TAG), now called the CTLT, designed a 4-hour training workshop called Developing your skills as a Peer Reviewer: Introductory workshop. To this day, we recommend that peer reviewers participate in this workshop to practice techniques they will use in a peer review. Thinking to the future, Cassidy and Johnson (2006) also designed an Advanced Workshop for trained colleagues who had completed several peer reviews. After this initial work, additional funding in 2009 and 2010 allowed workshops to be offered to a greater number of Faculties.

Some specialized workshops followed, such as for faculty within Pharmaceutical Sciences, and Teaching Assistants in Physics, Faculty of Science (co-facilitated by a Physics Teaching Assistant). A version of the workshop was modified as part of the Peer Teaching Network within Faculty of Science's Science Centre for Learning and Teaching (Cassidy $\&$ Lee, 2011).

As a broader Initiative, in 2008, a working group was tasked with developing principles and procedures for the formal summative evaluation of teaching, to inform decision making regarding reappointment, promotion and tenure. Principles include accuracy, integrity, transparency, diversity, credibility, and usefulness (Egan, 2010).

From 2010-2011, the working group initiated a program to train nominated representatives from each Faculty in the principles and practice of the summative peer review of teaching process. Those faculty members have been actively 
involved as leaders of the Summative PRT Program across UBC.

Today, each Faculty has developed and implemented a procedure suited for their individual needs. In some Faculties formative peer review of teaching is a mandatory process while in other Faculties it continues to be offered on a volunteer basis.

CTLT offers the Developing your skills as a Peer Reviewer: Introductory workshop three times per year to faculty members interested in learning more about both the formative and summative PRT process, as well as to those interested in learning the necessary skills needed in the peer review process. All interested participants are then invited to join a team of volunteer reviewers of the Formative PRT Program, described in more detail below. The three authors of this paper have all been reviewers in this program.

We also lead customized versions of the workshop on request. Over the past two years, we have designed and led such workshops for the Faculties of Forestry, Land and Food Systems, Law, Pharmacy, Sauder School of Business and Science as well as departments and other units such as Asian Studies, Botany, Cellular and Physiological Sciences, Electrical Engineering, Human Kinetics, Pathology, and Physics (for Teaching Assistants).

Additionally, over the past year, one of us (Golparian), in collaboration with CTLT colleagues, designed and implemented a customized PRT Program for Asian Studies, including reviewer training workshop development and facilitation, resources development, and program coordination. The program which consists of a 1.5 year long cycle of two formative peer reviews and a summative peer review, is required by all lecturers chosen to undergo this process. Golparian continues to offer consultation on the coordination of this program in her new role at CTLT.

Now near the end of the second part of the cycle, Golparian has been in consultation with reviewers, reviewees and the department head, with program evaluation and redesign taking place throughout the process. The third phase of the first cycle, Summative reviews will take place in the fall of
2015. In the meantime, the second round of the program started in January 2015 and the feedback from the first round of reviews (from both reviewers and reviewees) will inform the modification and the redesign of the program for the second round.

CTLT has also been actively involved in Summative PRT processes at UBC. Leaders within faculties meet twice a year to discuss successes and challenges and to modify/redesign their implemented processes.

In 2014, in consultation with Dr. Simon Bates, CTLT Academic Director, one of us (Golparian) developed a program evaluation survey for formative and summative peer review of teaching processes at UBC. The survey, which was sent out to all faculty members at UBC, received 100 responses. These responses provide us with a list of challenges and opportunities that reviewers and reviewees have experienced as part of the Summative and Formative PRT processes, and highlight several action items including the need for clarification and better communication around the PRT process (i.e.: the importance of pre and post observation meetings; Faculty specific standards). Results, presented to the leaders of the Summative PRT Initiative, are being used to make decisions around the redesign of each of their faculties' peer review processes.

\section{The Process of the Formative Peer Review of Teaching Program}

The PRT workshop that we offer at the CTLT is designed to support reviewers and reviewees in both Summative and Formative PRT processes. The workshop provides reviewers with an opportunity to acquire and practice skills needed to conduct peer reviews of teaching, and it provides reviewees with an opportunity to familiarize themselves with the peer review of teaching as well as their roles and responsibilities throughout the process.

The processes for Formative (for developmental and mentoring purposes) and 
Summative (for reappointment and hiring purposes) reviews are different in each Faculty and/or department, however all processes (should) involve a pre-observation meeting, an observation and a postobservation meeting. The following explains a generic process for a formative peer review of teaching:

To request a formative peer review of teaching, reviewees usually contact potential peer reviewers who would be listed on the department website. In certain cases reviewees are assigned to reviewers by the department and are then asked to communicate/connect with them. Formative reviews are often voluntary, however, in some departments, they are mandatory.

Whether the formative peer review is voluntary or mandatory, a reviewee contacts reviewers and provides the following information:

- Contact information

- Aspect(s) of their teaching they would like to have reviewed. These could include:

o Classroom teaching (e.g. first year math class with more than 100 students, graduate seminar with 4 people, Problem Based Learning session)

o Course design

o Student assignments

o Student supervision

o Teaching dossier and/or other teaching materials

o Other materials as requested

If the reviewee would like the reviewer to conduct a classroom observation, the reviewee then suggests possible dates, or a time frame and talk or email to set up details of a pre-observation meeting, classroom observation(s), and a post-observation meeting.

After the classroom observation, the reviewees reflect on what happened during the class and whether they feel they accomplished their objectives for the day. They record any issues or events that they would like to discuss with their peer reviewer. During the post-observation meeting, they review, reflect on, and possibly also respond to the peer reviewer's feedback report. Finally, reviewees decide whether or not to submit the peer reviewer's report (along with their own) to their employment file and/or to include it in their teaching portfolio/dossier.

\section{Key Elements of the STLHE Session}

We involved participants throughout the session, at the same time modelling some of the techniques, especially active listening and role-playing that form part of the workshop to become a peer reviewer. We invite you to modify the elements below for your own use.

\section{Index Card Question}

As people came into the room, we wanted to involve them right away. We asked them, in 10 words or less (noting that it would be shared with others), to write their answer to the following question on an index card: How does peer review of teaching (PRT) help students learn?

\section{Role Play}

We modelled a typical interaction between reviewer and reviewee in the pre-observation meeting. We did this to set the tone for the session and show in a real way how the pre-observation meeting works. We also wanted participants to reflect and draw on their personal experience to ask questions and share their experiences (Mundy \& Chan, 2013).

\section{Debrief and Overview of the Process}

We explained that the pre-observation meeting is one of the three parts of the PRT process. A hand-out that noted each part, with links was distributed (Cassidy \& Johnson, 2010). 


\section{Poll}

We asked the following questions, asking for a show of hands to answer each:

- How many of you conduct peer reviews of teaching?

- Did you do a training for it or not? Was it for formative or summative purposes?

- Was it official or informal?

- How many people do it some other way? Ask participants to share some experiences?

- Was the review voluntary (requested by the reviewee) or mandatory?

\section{Discussion}

The above activity led to an open discussion about the various ways to conduct PRT. At this time we also read out some of the index card contributions. We ask participants to share best practices as well as challenges in PRT.

Based on examples generated by participants of the STLHE session, as well as participants of other peer review workshops we have led, we present a list of best practices in the peer review of teaching (listed in alphabetical order):

- Ask reviewee how they feel/think the teaching went - invite their in-depth reflection (in post-observation meetings)

- Be sensitive to needs of reviewee

- Be specific

- Clarify purpose of the review (in preobservation meetings)

- Check how teaching resources and lesson plans are aligning with existing curriculum

- Confirm confidentiality (formative reviews)

- Focus on goals identified in the preobservation meetings (in postobservation meetings and for formative reviews)
- Have a frank exploration of what's possible in terms of outcomes

- Help address any fears of being reviewed-provide reassurance

- Offer an initial recap of pre-observation meeting (in post-observation meetings)

- Offer tips to improve teaching

- Present reasoning

- Revisit confidentiality and purpose (in post-observation meetings)

- Show a sense of empathy

- Share examples of other teaching techniques

- Sit beside, not across

- Smile, be welcoming, friendly and open

- The process should be a dialogue

- Tie into the reviewee's objectives and provide specific feedback as requested by the reviewee (in post-observation meetings and for formative reviews)

- Validate first (identify/share strengths)

- Work with rather than against

Similar lists are generated during customized PRT workshops in each Faculty and department as guidelines for their Peer Review of Teaching best practices. Each customized list reflects the culture of individual Faculties and departments.

Many of the contributions also served as a debrief of what STLHE session participants saw happening during the role play of a pre-observation meeting. This mirrors what we do in the actual workshop.

\section{Next Steps}

CTLT continues its involvement with the PRT Initiative at UBC, such as offering the Introductory and Advanced workshops as well as customized versions for departments and faculties.

Based on the 2014 PRT Program Evaluation Survey results, one of us (Golparian) has recommended that CTLT develop the Peer Review of 
Teaching Program so that it would include additional training workshops on Classroom Observation Criteria and Process, Best Teaching Practices, Providing Constructive Feedback, and Developing/Writing a Peer Review of Teaching Report.

Since the design and implementation of the customized program in Asian Studies, CTLT has been contacted by a few other departments at UBC for support around the development of departmentspecific PRT Programs. We anticipate that other departments and faculties will also be contacting us for support around PRT Program design and additional customized workshops and programs. This process will be customized to suit the needs of individual departments (Toth \& McKey, 2010).

We will also need to draw on the experiences from current active peer reviewers to understand modifications and adaptations made to the 3-step process originally developed. For instance, one of us (Chan) has conducted Small Group Instruction Feedback as requested by a reviewee, immediately after her classroom observation. In other cases preliminary reports were prepared prior to the postobservation meetings and subsequently revised after the meeting with the reviewee. These modifications, as well as those documented by Bell and Cooper (2013), Buskist et al. (2014), and Hitchens (2014) should inform future development of the Peer Review of Teaching process.

CTLT is also in the process of developing a Peer Review Program for Graduate students, consisting of two components: Peer Review of Teaching and Peer Review of Presentations. The goal is to support graduate students in improving their teaching and presentations skills. Future information about this program can be found on the CTLT website. CTLT will also continue to share its experiences with the wider Peer Review of Teaching community and engage in conversations with other Educational Developers who are actively involved in the design, development and evaluation of such programs.

\section{References}

Bell, M., \& Cooper, P. (2013). Peer observation of teaching in university departments: a framework for implementation. International Journal for Academic Development, 18, 60-73. http://dx.doi.org/ 10.1080/1360144X.2011.633753

Buskist, W., Ismail, E. A., \& Groccia, J. E. (2014). A practical model for conducting helpful peer review of teaching (Chapter 3). In J. Sachs \& M. Parsell (Eds.), Peer review of learning and teaching in higher education. Springer: New York. Professional Learning and Development in Schools and Higher Education, 9, 33-52. http://dx.doi.org/ 10.1007/978-94-007-7639-5_3

Cassidy, A., \& Johnson, J. (2006). Developing your skills as a peer reviewer: Introductory workshop handbook. Centre for Teaching and Academic Growth (now Centre for Teaching, Learning and Technology). University of British Columbia. Retrieved from http://wiki.ubc.ca/Documentation: CTLT_programs/PRT/UBC_docs

Cassidy, A., \& Johnson, J. (2010). Faculty Peer Review of Teaching. Retrieved from http://ctlt.ubc.ca/programs/all-our-program s/peer-review-of-teaching/

Cassidy, A., \& Lee, J. (2011). Peer review: Structured, informal, confidential, helpful! Collected Essays on Learning and Teaching, 4, 68-73. http://celt.uwindsor.ca/ojs/leddy/ index.php/CELT/index

Chism, N. (2007). Peer review of teaching: $A$ sourcebook ( $2^{\text {nd }} \mathrm{ed}$.). Bolton, MA: Anker Publishing Company, Inc.

Egan, J. (2010). UBC Peer Review of Teaching Initiative. Retrieved from http://ctlt.ubc.ca/ 
about-isotl/programs-events/ubc-peerreview-of-teaching-initiative/

Gosling, D. (2014). Collaborative peer-supported review of teaching. In J. Sachs \& M. Parsell (Eds.), Peer Review of Learning and Teaching in Higher Education. New York, NY: Springer. Professional Learning and Development in Schools and Higher Education, 9, 13-31. http://dx.doi.org/10.1007/97894-007-7639-5_2

Hitchens, A. (2014). Six questions. In J. Sachs \& M. Parsell (Eds.), Peer Review of Learning and Teaching in Higher Education. New York, NY: Springer. Professional Learning and Development in Schools and Higher Education, 9, 85-102. http://dx.doi.org/10.1007/97894-007-7639-5_6

Mundy, A., \& Chan, J. (2013). Visualizing boundaries and embodying conflicts: Lessons learned from a theatrical professional development program. Collected Essays on Learning and Teaching, 6, 41-47. http://celt.uwindsor.ca/ojs/leddy/index.php/ CELT/index

Scriven, M. (1973). The methodology of evaluation. In B. R. Worthen \& J. R. Sanders (Eds.), Educational evaluation: Theory and practice (pp. 60-104). Belmont, CA: Wadsworth.

Toth, K. E., \& McKey, C. A. (2010). Differences in faculty development needs: Implications for educational peer review program design. Canadian Journal of Higher Education, 40(1), 53-69. http://ojs.library.ubc.ca/index.php/ cjhe/index

\section{Acknowledgements}

We thank the anonymous reviewers, whose comments and suggestions helped us to improve this paper.

\section{Biographies}

Shaya Golparian, Ph.D., is an Educational Developer: TA Development Programs Coordinator, at the Centre for Teaching, Learning and Technology (CTLT), in the University of British Columbia. Shaya coordinated the Peer Review of Teaching Program at CTLT between April 2013 and August 2014 and has also conducted peer reviews as part of this program.

Judy C. K. Chan, Ph.D., is an Educational Developer, Faculty Programs, at the Centre for Teaching, Learning and Technology (CTLT) and a sessional lecturer at the Faculty of Land and Food System (LFS) at the University of British Columbia. She was a member of the ad hoc formative peer review committee in LFS and continues to conduct peer reviews as part of her educational developer role.

Alice Cassidy, Ph.D. is an Educational Developer, workshop and program designer and facilitator in the Faculties of Science and Land and Food Systems (LFS) at the University of British Columbia. In 2006, she co-designed the Peer Review of Teaching Program at the Centre for Teaching and Academic Growth (TAG), now called the Centre for Teaching, Learning and Technology CTLT, including the 4hour workshop and advanced workshops that are offered today. 


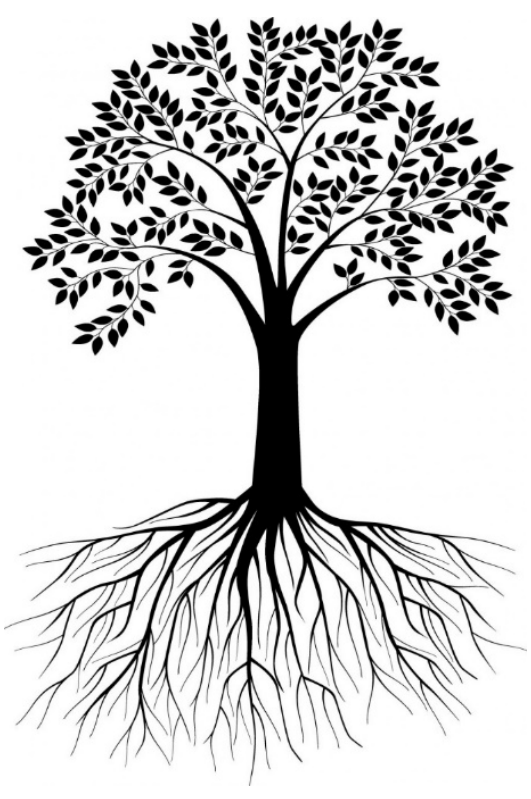

